\title{
U.S. Dental School Deans' Attitudes About Mid-Level Providers
}

\begin{abstract}
Mert N. Aksu, D.D.S., J.D., M.H.S.A.; Elizabeth Phillips, Ph.D.; H. Luke Shaefer, Ph.D.
Abstract: The introduction of mid-level providers to the U.S. dental workforce is currently a topic of heated debate. As little is known about the opinions of those who educate oral health professionals on the subject of such practitioners, a survey of U.S. dental school deans was undertaken to gauge their attitudes about alternative workforce models in the dental profession. The survey was sent to deans of the then-fifty-eight U.S. schools of dentistry; forty-four responded for a 76 percent response rate. Over three-fourths of the respondents agreed that the scope of practice for both dental hygienists and dental assistants should be expanded; significantly, over half agreed that the future of dentistry should include a dental therapist-type practitioner. Moreover, three-fourths agreed that such practitioners or expanded-duty hygienists would improve access to care for the underserved, and between half and two-thirds agreed that the quality of care delivered by these professionals would not be a problem. The attitudes of the deans about mid-level providers falls somewhere between that reported for U.S. dentists generally, who tend to be skeptical, and for dentists in other countries, who, once they have worked in a system with dental therapists, tend to be supportive.
\end{abstract}

Dr. Aksu is Dean, University of Detroit Mercy School of Dentistry; Dr. Phillips is Research Associate, University of Michigan School of Social Work; and Dr. Shaefer is Assistant Professor, University of Michigan School of Social Work. Direct correspondence and requests for reprints to Dr. Elizabeth Phillips, University of Michigan School of Social Work, Room 2753, 1080 S. University Ave., Ann Arbor, MI 48109; 734-764-6686; ehp@umich.edu.

Keywords: delivery of dental care, access to oral health care, dental hygienists, dental therapists, dental workforce, oral health professionals, mid-level providers, scope of practice, dental school deans

Submitted for publication 11/15/12; accepted 1/2/13

$\mathrm{T}$ There has been significant discussion recently among dental stakeholders on the subject of mid-level providers. Although the term is not precisely defined, it most often is associated with the creation of a new member of the dental workforce (the dental therapist) or an expansion of scopes of practice for existing members to include irreversible dental procedures. Although mid-level providers practice in a number of developed countries where they perform irreversible dental procedures, in the United States the practice has not yet been widely accepted. In this country, movement toward therapists and expanded-duty hygienists has been attributed to a number of nationally prominent foundations and advocacy organizations, as well as to governmental entities and even some dental organizations (e.g., the American Association of Public Health Dentistry) that have voiced a need for such providers as a means of improving access to oral health care for the underserved.

Few formal surveys have been conducted, however, about the attitudes and opinions of U.S. dentists toward various alternative workforce models, including the most commonly cited midlevel provider, the dental therapist. Likewise, little is known about the opinions of those who educate them, although this is potentially important as those individuals are responsible for creating an environment where professional values and culture develop in their students. Anecdotal evidence suggests that U.S. dentists are dubious at best. However, if international experience is any indication, hostile feelings often evolve, and once a particular model matures, attitudes change. Just as dentists were once skeptical of dental hygienists as were physicians toward physician assistants and nurse practitioners, in those places where mid-level dental providers (typically in the form of dental therapists) have been introduced and their training, scope of practice, and potential contribution have become better understood, professional support typically increases. In countries with practicing dental therapists, dentists are generally positive about the role they play. ${ }^{1}$

While few U.S. dental school deans have spoken publicly on the issue, the purview of schools of dentistry includes not only training new oral health professionals, but also looking to the future of the profession and adding to the general knowledge base. These roles suggest that dental school deans might be open-minded about exploring the value of 
a new provider as part of the dental team. The aim of our study was to gauge their views. We developed a survey and sent it to the deans of all Commission on Dental Accreditation (CODA)-accredited schools of dentistry in late 2010. The results of this survey are presented here and are discussed in relation to the findings from other studies that address the attitudes and opinions of dentists about mid-level providers.

\section{Previous Findings on Dentists' Attitudes About Mid-Level Providers}

\section{Studies in the United States}

We are aware of only two recent studies that address the attitudes of U.S. dentists toward dental therapists. One, by To'olo et al., ${ }^{2}$ surveyed U.S. pediatric dentists. Surveys were sent to all 1,673 boardcertified pediatric dentists; the response rate was 25 percent. This study found that while the majority of the respondents (75 percent) were not particularly knowledgeable about therapists and their training and only 21 percent were knowledgeable about how they were being used in Alaska, 71 percent disagreed with the idea of adding pediatric oral health therapists to the U.S. dental team. In fact, only 8 percent supported the idea, while the rest were neutral. Among those who disagreed with adding therapists, 57 percent cited lack of clinical training, and 26 percent cited lack of need as primary reasons. Those who supported the idea of adding therapists were more likely to work in public health, academic, or hospital settings than to be in private practice. Likewise, those treating higher proportions of Medicaid patients were more supportive; however, even among those with most of their clinical income derived from Medicaid/ Children's Health Insurance Program (CHIP), the majority still disapproved of the idea. Those who were either supportive or neutral were asked a set of follow-up questions, including whether they would likely hire a therapist if it were an option and whether they thought hiring a therapist would allow them to treat more Medicaid children. Of these respondents, 50 percent responded that they would hire a therapist, and 26 percent agreed that hiring a therapist would allow them to treat more Medicaid patients. Nearly all of the pediatric dentists who agreed therapists should be added to the dental team believed it would improve access to care; among those who disagreed with the concept of therapists, 75 percent said they would not help the access problem.

The other recent study undertaken in the United States surveyed University of Minnesota dental school faculty members in the first year (2009) of that state's (and university's) dental therapist training program. ${ }^{3}$ Minnesota is the only U.S. state other than Alaska where dental therapists currently practice. Lopez et al. sought to gauge the faculty members' perceptions and attitudes toward the new practitioner the school had been tasked with educating. Surveys were sent to all 303 full- and part-time faculty members in the School of Dentistry; the response rate was 55 percent. The vast majority ( 92 percent) taught D.D.S. students, while 8 percent were on the dental hygiene faculty. Overall, these researchers found that while the faculty members felt personally responsible for treating the underserved and for properly preparing their new students, they nevertheless were not particularly in favor of dental therapists. That survey found that female and younger faculty members were more open to the idea of therapists than were their older, male colleagues; it also uncovered a strong difference of opinion toward therapists between full- and part-time faculty members, the latter also tending to practice privately. Specifically, as to whether therapists will "be part of the solution to the problem of access to care in the state," overall 30 percent agreed, 44 percent disagreed, and the rest said they were not sure. However, among those who were also in private practice, only 20.5 percent agreed, while 44 percent of those not working outside the school responded they would. Likewise, only 30.5 percent of responding faculty members reported thinking that therapists would increase the number of dental practices willing to provide treatment to publicly insured patients. The faculty members were also asked whether they felt they had a good understanding of the role of dental therapists and whether they thought the level of training they would receive was adequate for the duties they would take on. Interestingly, only 58 percent answered yes to the first question and 27 percent to the second (45 percent said they did not know).

These two studies suggest that a considerable lack of knowledge exists in the U.S. dental community regarding the training and potential role of dental therapists. There is also a general doubt about these professionals' usefulness and considerable disagreement as to whether therapists should be added to the U.S. oral health care team and whether they are likely 
to ease the access to care problem. Academics and those employed in public settings or treating more publicly insured patients are more likely to be supportive of the concept and to agree that therapists have a role to play in increasing access to care than are those in private practice. Both To'olo et al. and Lopez et al. suggest that economic motivations (and/ or fears) may be playing a role in this viewpoint. An alternative explanation is that those in academic and/ or public settings may be more aware of the international literature on dental therapists.

\section{Studies from Abroad}

Since dental therapists practice in other countries, it is perhaps illustrative to consider how the knowledge and attitudes of dentists practicing in those countries compare to opinion in the United States. A series of studies on the topic have been conducted in the United Kingdom. Therapists there have practiced in public settings for over forty years, but only recently (2002) were they permitted to work in private settings. These studies are potentially informative as we can observe to what extent understanding and opinion change both over time and as the role of therapists has expanded.

In the early 1980s, Woolgrove and Harris conducted a national survey of British dentists to ascertain their opinions about delegation to therapists. ${ }^{4}$ They found that younger dentists and those working for the Community Dental Service were more supportive of a team approach than were older dentists and those working in general practice. Overall, 37 percent responded they should be able to delegate simple fillings, with the figure rising to 58 percent among community dental officers. Likewise, 40 percent of recent graduates supported delegating fillings, while only 26 percent of older dentists did. An age/practice differential was repeated in a study conducted roughly ten years later by Hay and Batchelor, who surveyed a random sample of district dental officers and general dentists and found that younger dentists and those in public service were more likely to support the idea of therapists in private practice than were general dentists (62 versus 48 percent). ${ }^{5}$ Among the general dentists who objected to therapists in private settings, the most common reason given was that they were not necessary; only 10 percent questioned their clinical competence. In the years between these two surveys, dentists objecting to others being able to employ therapists decreased from 27 percent to 20 percent.
A decade later, Gallagher and Wright surveyed general dentists in West Sussex just prior to therapists entering the private sector. ${ }^{6}$ The majority of respondents had a favorable attitude toward therapists, with 70 percent agreeing that therapists can make a meaningful contribution to the dental team (only 4 percent disagreed). In that sample, only 2 percent disagreed that there is evidence that therapists perform high-quality work (though nearly half said they did not know). Two studies were subsequently conducted shortly after therapists were permitted to work in the private sector. Ross et al. surveyed practicing dentists in Southeast Scotland ${ }^{7}$ and Jones et al. surveyed general dental practitioners in Wales ${ }^{8}$ about their knowledge and attitudes toward dually trained hygienist-therapists. In both cases, the dentists expressed overwhelmingly positive attitudes toward therapists, with 85 percent of the respondents in the Ross et al. study agreeing that hygienist-therapists have a useful contribution to make and 60 percent of those in the Jones et al. study agreeing they would reduce workload for dentists and 55 percent that therapists would improve access to dentistry for patients.

All three of the studies conducted prior to therapists entering the private sector in the United Kingdom found that roughly 40 percent of the general dentists surveyed said they would or would consider employing a therapist were it legal to do so. In fact, only 23.5 percent of the respondents in the survey conducted by Gallagher and Wright said they would not, with financial considerations posing the biggest barrier. ${ }^{6}$ In each of the two studies conducted in 2007, fewer than 10 percent of the dentists surveyed were currently employing a therapist, though 64 percent of the Scottish dentists and 43 percent of the Welsh respondents thought they might hire one ( 9 percent of the latter already had). In both surveys, a primary reason offered for not hiring a therapist was lack of space-which was also the main reason given by dental officers in the earlier study by Hay and Batchelor. ${ }^{5}$ Concerns over costs and/or economic viability were cited by only 15 percent of the Scottish dentists, though roughly half of the Welsh dentists stated they did not know enough about the cost-effectiveness of hygienist-therapists in general practice.

Despite a generally positive attitude toward therapists and an increasing willingness to hire one, it appears that large gaps in knowledge persist. Gallagher and Wright found that, on the eve of entry into private practice, the majority of dentists they surveyed either answered incorrectly or did not know the answers to questions about who therapists were 
allowed to treat and the level of supervision required. ${ }^{6}$ Five years after therapists entered private practice, dentists were often not much better informed. Jones et al. found that dentists had little knowledge of the training and work practices of oral health therapists; they also found that there was "a clear lack" of understanding about how they could be utilized within a dental team. ${ }^{8}$ Likewise, Ross et al. found that, on about half the questions concerning remit, the dentists did well, but knowledge was lacking in a number of areas. Knowledge was greater among those working in practices employing a hygienist. These authors concluded that "significant education of dentists is necessary."

The general findings from these five British studies-in particular, the large gaps in knowledge and perceived barriers to employment-are echoed in studies from other countries. An early study conducted in Saskatchewan, Canada, on the eve of the introduction of that province's school dental program, found that dentists' attitudes toward using dental nurses (as therapists were then known) went from 2:1 against in 1970 to nearly evenly split in 1972 , presumably a result of becoming more knowledgeable as their introduction neared. At the same time, however, only 45 percent of the dentists surveyed said they would hire one. ${ }^{9}$

Recent studies in New Zealand and Australia, where therapists have been practicing for years though only recently in private settings, report similar findings. Moffat and Coates surveyed general dentists, dental specialists, and dental students in New Zealand..$^{10}$ They found that dentists' knowledge of therapists' skills, scope of practice, and practice requirements was limited in a number of areas. Even though employment in the private sector had been legal for five years, only 5 percent of the private dentists surveyed were employing one, though 59 percent said they would consider hiring a dually trained oral health therapist (that is, someone trained as both a dental hygienist and dental therapist). As was the case in other studies, working in a practice that already employed a hygienist or therapist made dentists significantly more likely to feel this way. As in the UK, the top reason given for not wanting to hire an oral health therapist was lack of space, with lack of demand and financial concerns also relatively important; only 18.5 percent cited clinical skill. A study by Burman of attitudes toward and utilization of therapists in Western Australia, where at the time they had been working in private settings for twenty years, found that only 20 percent of the dentists surveyed employed one and those that did mainly delegated hygienist duties. ${ }^{11}$ Only 15 percent stated that operative procedures made up the major functions performed by their therapist. Whether this was due to a lack of confidence, lack of need, or lack of understanding on the part of the dentist was not explored, though the author does mention underemployment of dentists in the state.

\section{Methods}

In November 2010, we sent a survey via email using SurveyMonkey to the deans of the then fifty-eight U.S. schools of dentistry. In accordance with U.S. Department of Health and Human Services Regulations for Protection of Human Subjects, the human subjects application for this project underwent exempt review by the University of Detroit Mercy's Institutional Review Board; it was approved as minimal risk to subjects.

The purpose of the survey was to determine the attitudes of dental deans regarding alternative workforce models in the dental profession and to compare their attitudes regarding dental mid-level providers to their attitudes regarding physician assistants and nurse practitioners. The survey respondents were asked whether they agreed (yes/no response) with twenty-four statements, based on what we called their "knowledge of national trends." In addition to asking for their attitudes about expanded duties for existing allied dental practitioners and adding mid-level providers to the dental workforce, the survey asked for respondents' opinions on matters related to access to care (a primary reason for introducing such providers); the demographic make-up of the profession and how to achieve a more diverse pool of dental school applicants (diversity being another hallmark of many dental therapy models); and their impression of the impact of mid-level providers in medicine.

\section{Results}

Forty-four surveys were returned, for a 76 percent response rate. Thirty-five deans ( 85 percent of those who responded to the question) had been educators for twenty years or more. Seventeen considered themselves to be general dentists, eighteen specialists, and four public health dentists; the remainder either did not answer this question or selected "Other." No other demographic information was collected in order to preserve anonymity of respondents. 
The survey findings are shown in Table 1. Among these dental school deans, it was well understood that the current U.S. dentist workforce is overwhelmingly male and Caucasian. However, with women currently making up roughly half of dental students nationwide, ${ }^{12}$ the former, at least, is rapidly changing. The dental school deans were also well aware of the fact that roughly a third of the children in this country depend on Medicaid for their medical (and dental) insurance (in 2010, the figure was 35 percent).$^{13}$ The majority also agreed that there are insufficient numbers of dentists to meet the needs of the public and that, over the next decade, this shortage will be exacerbated by fewer new dentists graduating than dentists retiring.

Table 1. U.S. dental school deans' agreement with statements about national trends, by number of respondents to each statement and percentage of those agreeing with statement

Statement

Over $75 \%$ of active practicing dentists are male.

Over $75 \%$ of active practicing dentists are white/Caucasian.

In any one year, roughly 1 in 3 children depend on Medicaid.

In the next ten years, it is projected that there will be fewer dentists graduating than dentists retiring.

There is a shortage of dentists to meet current needs of the public.

The issue of access to care for the underserved is primarily related to finances/ funding.

The issue of access to care for the underserved is primarily related to transportation.

The issue of access to care for the underserved is primarily related to dental IQ.

Underrepresented minority dental graduates are more likely than others to provide

Dental graduates from rural areas are more likely to return to practice in rural areas than graduates from non-rural areas.

Improving the access of K-12 rural students to regular oral health will increase the numbers of rural dental school applicants.

Improving the access of underserved minority K-12 students to regular oral health will increase the numbers of underrepresented minority dental school applicants.

Foreign-trained dentists should have easier avenues to licensure to improve access to care issues.

Nurse practitioners/physician assistants have improved access to medical care.

Nurse practitioners/physician assistants have reduced the cost of medical care.

Nurse practitioners/physician assistants have not negatively affected the quality of care provided to patients.

The future of dental practice should include an expanded scope of practice for existing dental hygienists.

The future of dental practice should include an expanded scope of practice for existing dental assistants.

The future of dental practice should include some sort of "mid-level" practitioner or "dental therapist."

The use of "mid-level" practitioners or "expanded duty" dental hygienists will reduce income for the dentist.

The use of "mid-level" practitioners or "expanded duty" dental hygienists will reduce the cost of dental care

The use of "mid-level" practitioners or "expanded duty" dental hygienists will improve access to dental care.

The use of "mid-level" practitioners or "expanded duty" dental hygienists will have no detrimental effect on the quality of dental care.

The use of "mid-level" practitioners or "expanded duty" dental hygienists will reduce the quality of dental care. services to underserved minority populations.

Percentage of Number of

Respondents Agreeing Respondents to with Statement Statement

\begin{tabular}{|c|c|}
\hline $80 \%$ & 42 \\
\hline $95 \%$ & 42 \\
\hline $80 \%$ & 40 \\
\hline $58 \%$ & 43 \\
\hline $60 \%$ & 43 \\
\hline $61 \%$ & 44 \\
\hline $18 \%$ & 44 \\
\hline $14 \%$ & 42 \\
\hline $81 \%$ & 43 \\
\hline $70 \%$ & 43 \\
\hline $61 \%$ & 41 \\
\hline $64 \%$ & 42 \\
\hline $33 \%$ & 40 \\
\hline $88 \%$ & 42 \\
\hline $36 \%$ & 39 \\
\hline $90 \%$ & 41 \\
\hline $80 \%$ & 41 \\
\hline $76 \%$ & 41 \\
\hline $55 \%$ & 40 \\
\hline $3 \%$ & 39 \\
\hline $33 \%$ & 40 \\
\hline $74 \%$ & 39 \\
\hline $51 \%$ & 39 \\
\hline $34 \%$ & 38 \\
\hline
\end{tabular}

Note: Instructions were worded as follows: "Based on your knowledge of national trends, do you agree with the following statements?" 
With respect to their opinions about other explanations for the access to care problem, 60 percent of the responding deans agreed that funding is the most important issue. Though not stated specifically, presumably this response relates to low Medicaid reimbursement rates. Far fewer deans agreed that the underserved themselves were to blame, with less than 20 percent agreeing with statements suggesting that transportation or low "dental IQ" were primary explanations. When asked about ways in which more dentists might be encouraged to practice in underserved areas, the deans overwhelmingly agreed that graduating dentists from rural areas were more likely to practice there and that underrepresented minority dentists were more likely to serve underrepresented minority patients. The evidence suggests that both of these statements are, in fact, true. ${ }^{14,15}$ Somewhat fewer of the respondents, though still a majority, agreed that improving access to oral health care for rural and minority children would lead to increased dental school applications from these underrepresented groups. Anecdotally, it is believed that if a member of an underrepresented minority group has access to care provided by a dentist from the same group, the patient might subsequently have an increased interest in that profession. Our survey respondents were less enthusiastic about easing licensure restrictions on foreign-trained dentists; only a third thought such a move would be a good idea.

The deans were next asked their impression of the impact mid-level providers have had in medicine. Though only about a third agreed that mid-level medical providers had reduced costs, the overwhelming majority agreed that nurse practitioners and physician assistants had improved access to medical care, while not negatively affecting the quality of care. Available evidence suggests that all three of these statements are in fact correct: mid-level providers in medicine have reduced costs and improved access, without lowering the quality of care. ${ }^{16-19}$

The rest of the survey addressed the deans' perceptions about the future role of allied dental professionals. Three-quarters agreed that the scope of practice of both dental hygienists and dental assistants should be expanded, and, significantly, over half agreed that the future of dentistry should include a dental therapist-type practitioner. Three-quarters agreed that such practitioners would improve access to care for the underserved, though only about a third agreed they would reduce costs. These feelings are consistent with the respondents' views about nurse practitioners. Notably, only a tiny fraction of the respondents agreed that the introduction of such providers would reduce income for dentists.

Two questions asked about the quality of care provided by mid-level practitioners. While a review of the literature indicates that dental therapists and dental hygienists trained in expanded duties provide safe quality care that is, within their limited scope of practice, at a level comparable to that of dentists, ${ }^{20}$ the dental school deans were less convinced of this. When asked whether they agreed that the use of midlevel providers or expanded duty dental hygienists would have no detrimental effect on the quality of dental care, the respondents were evenly split. When the question was phrased somewhat differently, asking whether the use of mid-level providers or expanded duty dental hygienists would reduce the quality of dental care, only a third agreed this would be the case. We do not have a good explanation for this difference, which may seem inconsistent. It may be related to the differential wording of the two statements. In any case, somewhere between half and two-thirds of the deans who responded to these questions agreed that quality of care was not an issue with respect to the future role of these dental professionals.

Overall, our study found that U.S. dental school deans were, perhaps not surprisingly, generally well informed on the subjects addressed in our survey. The majority were knowledgeable about the proportion of children with public insurance and the demographic make-up of the profession, as well as the types of practitioners who tend to treat the underserved. Very few appeared to think that the underserved themselves bear primary responsibility for their lack of care. The deans also understood that mid-level providers in medicine have improved access to care without lowering its quality, although they were less convinced that these providers have also reduced costs.

In terms of their attitudes about mid-level providers in dentistry, the majority of the responding deans agreed not only that dental hygienists and dental assistants should have expanded scopes of practice, but over half also agreed that the future of dental practice should include some sort of midlevel practitioner or dental therapist. Moreover, they agreed overwhelmingly that the introduction of such a provider would improve access to care and would not negatively impact dentists' incomes. Between half and two-thirds also agreed that introducing therapists would not negatively impact the quality of care that patients receive. 


\section{Discussion}

Among the interesting trends identified in this survey are the findings that dental school deans are generally supportive of the concept of mid-level providers or expanded duty dental hygienists and that they do not see them as a threat to the profession but rather as a possible solution to the access to care problem. These findings are consistent with the literature suggesting both that dentists working in public or university settings are more positively inclined toward mid-level providers than are dentists in private practice and that opinions regarding these providers tend to be related to feelings about whether such a workforce member will address the access to care problem. It is possible that the deans responding to our survey were somewhat more supportive of expanding the scope of existing members of the dental workforce (dental hygienists, dental assistants) than introducing a new member (dental therapists) because national educational standards already exist for the former and supervisory responsibilities are already defined. In the national debate surrounding the possible introduction of dental therapists to the U.S. oral health workforce, education and supervision are among the most divisive topics.

Previous studies have suggested that, despite evidence that dental therapists are safe providers of care, ${ }^{20}$ U.S. dentists overall are skeptical of their potential contribution, tending to be concerned about training and quality of care, perhaps as well as about the economic implications of a new provider. ${ }^{2,3}$ This is maybe not surprising since U.S. dentists have had little exposure to these practitioners. Internationally, however, there appears to be an evolution of dentists' attitudes in relation to how long and in which settings mid-level providers practice. Kravitz and Treasure interviewed dentists in several countries about their views towards the utilization of dental auxiliaries. ${ }^{21}$ New Zealand, the UK, and Canada were among the included countries, as were several in which therapists do not practice. They found that in New Zealand, the country with the longest dental therapy history, dentists largely viewed them with "apathy" and little fear of competition. In Canada, on the other hand, where therapists do not widely practice, dentists tended to support their use in remote communities but viewed their entrance into private practice as "cheap competition." In the UK, views have progressed with time, and the increasing scope of practice now "seemed to be welcomed by all parties."
The attitudes of U.S. dental school deans in our study seemed to fall somewhere between those of U.S. dentists generally and dentists internationally. It may be that the deans have a different vantage point than practicing dentists-focusing more on the future of the profession and having fewer personal reasons to feel threatened, although deans do need to be sensitive to the opinions of, and challenges facing, their alumni base. Anecdotal evidence suggests that deans of U.S. dental schools are often criticized for not fully understanding the issues facing private practice dentists. It has even been suggested by some that dental schools might support yet another member of the dental workforce for the main purpose of increasing enrollment in a new line of business. The educational and experiential backgrounds of dental deans suggest, however, that many are well versed in public policy and professional practice issues. Moreover, dental schools have experienced a rapid increase in numbers of applicants in recent years, and demand for entrance is adequate to meet enrollment demands of all dental schools in the United States without adding additional academic programs. Dental schools have many diverse stakeholders, and on the issue of alternative workforce models, the issues often create conflict among the various groups.

Untreated dental disease remains a major public health concern in the United States. Dental schools, through their clinical programs, often act as safetynet providers. Despite the impact made by dental schools and other nonprofit or public organizations, the issue of unmet dental need exceeds current safetynet capacity. Over one-third of U.S. households report skipping dental care or dental examinations because of cost, ${ }^{22}$ and dental caries is the single most common chronic disease of childhood. ${ }^{23}$

Up until the most recent recession, dentistry has enjoyed above average increases in annual income. While most dentists in private practice have the ability to treat more patients, the current delivery system and associated high costs of delivering care are not in balance with the ability of those who need care to pay, either directly or through third-party reimbursement. A recent decline in the consumption of dental services has been attributed to stagnant reimbursement for public assistance programs, as well as sharp declines in private insurance enrollment. ${ }^{24}$ In response to these issues, numerous alternative workforce models have been suggested to help close the access gap and even leverage the ability of dentists to see more patients at lower reimbursement rates by either utilizing "practice extenders" or expanding the scopes of 
practice of existing members of the dental team. The profession and the public should expect that a "single standard of care" is adhered to and that the current high standard of dental care received by those who already access the system is not threatened. Dental education is expensive, and dentists must have the economic opportunity to recover the actual and opportunity costs of their education. Careful and critical assessment of the manner in which care is delivered may create opportunities for dentists to deliver certain procedures more efficiently while focusing on those skills needed to ensure the health of the public.

Workforce matters are emotionally charged, and as a result it is sometimes difficult to engage in scholarly debate about them. As an evidence-based profession, decisions regarding workforce models must be based on research, not on emotion. Health care professions have the responsibility to critically assess themselves and adjust their practice to what the evidence suggests is prudent and proper in order to achieve high-quality public health outcomes. A profession changes by staying focused on its mission and understanding that the process is only part of the equation.

\section{Acknowledgments}

This research was supported in part by a grant from the Nokomis Foundation.

\section{REFERENCES}

1. Nash DA, Friedman JW, Mathu-Muju KR. A review of the global literature on dental therapists (in the context of the movement to add dental therapists to the oral health workforce in the United States). Battle Creek, MI: W.K. Kellogg Foundation, 2012.

2. To'olo G, Nash DA, Mathu-Muju KR, Mullins MR, Bush HH. Perspectives of board-certified pediatric dentists on adding a pediatric oral health therapist to the dental team. Pediatr Dent 2010;32(7):505-12.

3. Lopez N, Blue CM, Self KD. Dental school faculty perceptions of and attitudes toward the new dental therapy model. J Dent Educ 2012;76(4):383-94.

4. Woolgrove J, Harris R. Attitudes of dentists towards delegation. Br Dent J 1982;153(9):339-40.

5. Hay IS, Batchelor PA. The future role of dental therapists in the UK: a survey of district dental officers and general dental practitioners in England and Wales. Br Dent J 1993; 175:61-5.

6. Gallagher JL, Wright DA. General dental practitioners' knowledge of and attitudes towards the employment of dental therapists in general practice. Br Dent J 2003;194(11): 37-41.

7. Ross MK, Ibbetson RJ, Turner S. The acceptability of dually qualified dental hygienist-therapists to general dental practitioners in southeast Scotland. Br Dent J 2007; 202:E8
8. Jones G, Devalia R, Hunter L. Attitudes of general dental practitioners in Wales towards employing dental hygienisttherapists. Br Dent J 2007;203:E19.

9. Thomson HE, Mann JR, McPhail CWB. Dentists' attitudes to prepaid children's dental care programs and expanded care duty dental auxiliaries in Saskatchewan. J Can Dent Assoc 1973;39(1):47-54.

10. Moffat S, Coates D. Attitudes of New Zealand dentists, dental specialists, and dental students towards employing dual-trained oral health graduates. Br Dent J 2011;211:E16.

11. Burman NTC. Attitudes to the training and utilization of dental auxiliaries in Western Australia. Aust Dent J 1987;32(2):132-5.

12. American Dental Education Association. Survey of dental school seniors, 2011 graduating class. At: www.adea.org/ publications/library/ADEAsurveysreports/Pages/ADEASurveyofDentalSchoolSeniors2011GraduatingClass.aspx. Accessed: March 13, 2012.

13. Child trends. At: www.childtrendsdatabank.org/sites/ default/files/26_Health_Care1.pdf. Accessed: October 4, 2012.

14. McFarland KK, Reinhardt JW, Yaseen M. Rural dentists: does growing up in a small community matter? J Am Dent Assoc 2012;143(9):1013-9.

15. Andersen RM, Carreon DC, Davidson PL, Nakazono TT, Shahedi S, Gutierrez JJ. Who will serve? Assessing recruitment of underrepresented minority and low-income dental students to increase access to dental care. J Dent Educ 2010;74(6):579-92.

16. Bassinger RL, Allred CA, Arford PH, Bellig LL. A costeffectiveness analysis of neonatal nurse practitioners. Nurs Econ 1997;15(2):92-9.

17. Office of Technology Assessment, U.S. Congress. Nurse practitioners, physician assistants, and certified nursemidwives: a policy analysis. Health technology case study 37. Washington, DC: U.S. Government Printing Office, 1986.

18. Salkever DS, Skinner EA, Steinwachs DM, Katz H. Episode-based efficiency comparisons for physicians and nurse practitioners. Med Care 1982;20(2):143-53.

19. Nelson EC, Jacobs AR, Cordner K, Johnson KG. Financial impact of physician assistants on medical practice. New Engl J Med 1975;293(11):527-30.

20. Phillips E, Shaefer HL. Dental therapists: evidence on technical competence. J Dent Res 2013;92:S11-S15.

21. Kravitz AS, Treasure ET. Utilization of dental auxiliaries: attitudinal review from six developed countries. Int Dent J 2007;57(4):267-73.

22. Kaiser Family Foundation. Kaiser health tracking poll, February 2009. At: www.kff.org/kaiserpolls/upload/7866. pdf. Accessed: November 1, 2012.

23. Oral health in America: a report of the surgeon general. Rockville, MD: U.S. Department of Health and Human Services, National Institute of Dental and Craniofacial Research, National Institutes of Health, 2000.

24. American Dental Association. Breaking down barriers to oral health for all Americans: the role of finance. At: www.ada.org/sections/advocacy/pdfs/7170_Breaking_Down_Barriers_Role_of_Finance-FINAL4-26-12. pdf. Accessed: November $\overline{1}, \overline{2012 .}$ 